In such weather as we had the ascent of Ben Nevis is decidedly more pleasant and less fatiguing than in summer. It is well, however, to warn the readers of NATURE that our case was exceptional, and that under adverse circumstances such an enterprise is likely to be both unpleasant and dangerous.

G. ChRYSTAL

\section{THE REMARKABLE SUNSETS}

I

NFORMATION with regard to these beautiful phenomena and their cause is rapidly being collected, and at the same time the opinions of those who have given most attention to them are being stated, both here and on the Continent. Among the latter we may refer to a memoir presented by Prof. Forel to the Société Vaudoise des Sciences Naturelles, on the Igth of December. At the beginning of the displays in Switzerland, M. Forel ascribed them to those causes which produce the ordinary after-glow so beautifully visible in mountainous countries, and at first he considered that the meteorological conditions were such as to favour this view. Further inquiry, however, he now states has made this hypothesis absolutely untenable. One of his arguments is that the glows which first appeared in November and then decreased to 3rd December, regained a maximum on the 24 th and 25 th. Now from the 22nd to 26 th December, Switzerland was the centre of a maximum of atmospheric pressure, the barometer being higher there than in any of the surrounding countries. Exactly the opposite held in November, and this confirms him in the idea that meteorological factors alone do not suffice to explain the glows. He also describes the dates and tracts of the chromatic phenomena observed, and considers that their origination in Krakatoa is a simple and sufficient explanation. $L a$ Nature for the 29th ult. contains an interesting communication from M. Van Sandick, an Engineer des Ponts et Chaussées, at Pedang, who was an eye witness of the later stage of the eruption. $\mathrm{He}$ was on board the Governor-General Loudin, and was close to Krakatoa on August 26th. His communication is accompanied by a very detailed map, showing the changes which have supervened not only in the Straits themselves, but also on the neighbouring coasts of Java and Sumatra, but we shall return to this important letter.

The new observatory on the summit of Ben Nevis has been utilised for the collection of snow, with a view of determining whether or not it contains any dust particles. This has been forwarded to Mr. John Murray of the Challenser Commission by $\mathrm{Mr}$. Omond the superintendent of the observatory. We may hope to hear soon whether the results are positive or negative on this special point of inquiry. We have to call attention to the important letter of Mr. Macpherson published below. We learn from the Weekly British Colonist, published at Victoria, British Columbia, that the sunsets made their appearance there on November 27th. Long after sunset the light in the sky became more fervent in colour, till at last the waters in the harbour and straits borrowed the splendid crimson. Darting and rapidly moving blood-red rays of light were seen shooting far into the sky, suggesting an aurora. A letter from St. Raphael, on the shores of the bay of San Francisco, dated December 4th, refers to the magnificent sunrises and sunsets. The date of their commencement is not stated. From Kiakhta, on the Mongolian frontier, we learn that the glows there began on December i ith, and terminated on the 25 th.

The glows were seen some time before November 6 th at Kalim Pons, twenty miles north-west of Darjeeling.

We have received the following further communications on this subject:- -

THE body of evidence now brought in from all parts of the world must, I think, by this time have convinced $\mathrm{Mr}$. Piazzi Smyth that the late sunrises and sunsets do need some explanation, more particular than he was willing to give them. With your leave $I$ should like to point out from my own observations and those of others that, "given a clear sky" and the other conditions put by $\mathrm{Mr}$. Smyth, the sunrises and sunsets of other days, however bright and beautiful, have not given any such effects as were witnessed, to take an instance, here on Sunday night, December 16th. I shall speak chiefly of the sunsets.

(I.) These sunsets differ from others, first in their time and their place or quarter. Sunset proper is, I suppose, the few minutes between the first dipping and the last disappearance of the sun's disk below the true horizen; the pageant or phenomena we call sunset, however, includes a great deal that goes on before and after this. The remarkable and specific features of the late sunsets have not been before or at sunset proper; they have been after-glow's, and have: lasted long, very long, after. To

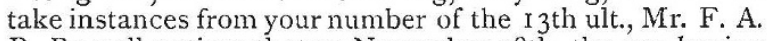
R. Russell notices that on November 28 th, the sun having set at 3.55, one after-glow lasted till 5.ro, and was then succeeded by another "reaching high above the horizon." The day before he mentions the after-glow as lasting to 5.20. On the 29th a "foreglow" is reported as seen in London from 5.30 to 7.30 , that is more than two hours before sunrise, which was at 7.43. On December Ist, sunset being at 3.53 , Mr. Russell observed an after-glow till 5.35 ; on December 4 th the first dawn at 6.5 , the sun rising at 7.50 ; the next day dawn at the same time, sunrise 7.51 ; that evening, sunset being at 3.50 , he observed not a glow only but "spokes of rays from the glowing bank" at 4.45 , thatis to say, sunbeams, visible in the shape of sunbeams, 55 minutes after sunset. Mr. JohnstonLavis speaks of the after-glow at Naples as at $a$ maximum an hour after sunset. Here at Stonyhurst on December 16th, the sun having set at 3.49, the glow was observed till 5.50. Now winter dawns and after-glows do not last from an hour to two hours, and still less so day after day, as these have done. The recent sunrises and sunsets then differ from others in duration.

They differ also in the quarter of the heavens where they are seen. The after-glows are not low lingering slips of light skirting the horizon, but high up in the sky, sometimes in the zenith.

I have further remarked that the deepest of the afterglow is in the south, whereas the sun below the horizon is then northing. I see that other observers take notice of the same.

(2) They differ in their periodic action or behaviour. The flushes of crimson and other colours after ordinary sunsets are irregular, not the same nor at the same time for two days together; for they depend upon the accidental shapes and sizes and densities of the cloud-banks or vapour-banks the sun is entering or freeing himself from, which vary and can never be alike from day to day. But these glows or flushes are noticed to be periodic before sunrise and after sunset. Mr. Russell furnishes exact estimates of the intervals of time, which he finds to be the same day after day.

(3) They differ in the nature of the glow, which is both intense and lustreless, and that both in the sky and on the earth. The glow is intense, this is what strikes every one; it has prolonged the daylight, and optically changed the season; it bathes the whole sky, it is mistaken for the reflection of a great fire; at the sundown itself and southwards from that on December 4 , I took a note of it as more like inflamed flesh than the lucid reds of ordinary sunsets. On the same evening the fields facing west glowed as if overlaid with yellow wax.

But it is also lustreless. A bright sunset lines the clouds so that their brims look like gold, brass, bronze, or steel. It fetches out those dazzling flecks and spangles which people call fish-scales. It gives to a mackerel or dappled cloudrack the appearance of quilted crimson 
silk, or a ploughed field glazed with crimson ice. These effects may have been seen in the late sunsets, but they are not the specific after-glow; that is, without gloss or lustre.

The two things together, that is intensity of light and want of lustre, give to objects on the earth the peculiar illumination which may be seen in studios and other welllike rooms, and which itself affects the practice of painters and may be seen in their works, notably Rembrandt's, disguising or feebly showing the outlines and distinctions of things, but fetching out white surfaces and coloured stuffs with a rich and inward and seemingly self-luminous glow.

(4) They differ in the regularity of their colouring. Four colours in particular have been noticeable in these after-glows, and in a fixed order of time and placeorange, lowest and nearest the sundown; above this, and broader, green ; above this, broader still, a variable red, ending in being crimson; above this a faint lilac. The lilac disappears; the green deepens, spreads, and encroaches on the orange; and the red deepens, spreads, and encroaches on the green, till at last one red, varying downwards from crimson to scarlet or orange fills the west and south. The four colours I have named are mentioned in Lieut. G. N. Bittleston's letter from Umballa: "The sun goes down as usual and it gets nearly dark, and then a bright red and yellow and green and purple blaze comes in the sky and makes it lighter again." I suppose the yellow here spoken of to be an orange yellow, and the purple to be what I have above called lilac.

Ordinary sunsets have not this order; this, so to say, fixed and limited palette. The green in particular, is low down when it appears. There is often a trace of olive between the sundown and the higher blue sky, but it never develops, that I remember, into a fresh green.

(5) They differ in the colours themselves, which are impure and not of the spectrum. The first orange and the last crimson flush are perhaps pure, or nearly so, but the two most remarkable glows, the green and the red, are not. The green is between an apple-green or pea-green (which are pure greens) and an olive (which is a tertiary colour): it is vivid and beautiful, but not pure. The red is very impure, and not evenly laid on. On the 4 th it appeared brown, like a strong light behind tortoiseshell, or Derbyshire alabaster. It has been well compared to the colour of incandescent iron. Sometimes it appears like a mixture of chalk with sand and muddy earths. The pigments for it would be ochre and Indian red.

Now the yellows, oranges, crimsons, purples, and greens of bright sunsets are beautifully pure. Tertiary colours may of course also be found in certain cases and places.

(6) They differ in the texture of the coloured surfaces, which are neither distinct cloud of recognised make nor yet translucent mediums. Mr. Russell's observations should here be read. I have further noticed streamers, fine ribbing or mackerelling, and other more curious textures, the colour varying with the texture.

In ordinary sunsets the yellows and greens and the lower reds look like glass, or coloured liquids, as pure as the blue. Other colours, or these in other parts, are distinct flushes or illuminations of cloud or landscape.

I subjoin an account of the sunset of the I6th, which was here very remarkable, from my own observations and those of one of the observatory staff.

A bright glow had been round the sun all day and became more remarkable towards sunset. It then had a silvery or steely look, with soft radiating streamers and little colour; its shape was mainly elliptical, the slightly longer axis being vertical; the size about $20^{\circ}$ from the sun each way. There was a pale gold colour, brightening and fading by turns for ten minutes as the sun went down. After the sunset the horizon was, by 4.10, lined a long way by a glowing tawny light, not very pure in colour and distinctly textured in hummocks, bodies like a shoal of dolphins, or in what are called gadroons, or as the Japanese conventionally represent waves. The glowing vapour above this was as yet colourless; then this took a beautiful olive or celadon green, not so vivid as the previous day's, and delicately fluted; the green belt was broader than the orange, and pressed down on and contracted it. Above the green in turn appeared a red glow, broader and burlier in make ; it was softly brindled, and in the ribs or bars the colour was rosier, in the channels where the blue of the sky shone through it was a mallow colour. Above this was a vague lilac. The red was first noticed $45^{\circ}$ above the horizon, and spokes or beams could be seen in it, compared by one beholder to a man's open hand. By 4.45 the red had driven out the green, and, fusing with the remains of the orange, reached the horizon. By that time the east, which had a rose tinge, became of a duller red, compared to sand: according to my observation, the ground of the sky in the east was green or else tawny, and the crimson only in the clouds. A great sheet of heavy dark cloud, with a reefed or puckered make, drew off the west in the course of the pageant : the edge of this and the smaller pellets of clond that filed acro:s the bright field of the sundown caught a livid green. At 5 the red in the west was fainter, at 5.20 it became notably rosier and livelier; but it was never of a pure rose. A faint dusky blush was left as late as 5.30 , or later. While these changes were going on in the sky, the landscape of Ribblesdale glowed with a frowning brown.

The two following observations seem to have to do with the same phenomena and their causes. For some weeks past on fine bright days, when the sun has been behind a big cloud and has sent up (perspectively speaking) the dark crown or paling of beams of shadow in such cases commonly to be seen, I have remarked, upon the ground of the sky, sometimes an amber, sometimes a soft rose colour, instead of the usual darkening of the blue. Also on moonlight nights, and particularly on December 14, a sort of brown or muddy cast, never before witnessed, has been seen by more than one observer, in the sky.

Stonyhurst College, December 2 I, $\mathrm{I}_{8} \mathrm{~S}_{3}$

THE remarkable phenomena after sunset which, according to NATURE, were seen in the second half of November in England, Italy, at the Cape, and a little earlier in many parts of Asia, could be observed almost all over Austria and Germany. I saw them myself in an especially distinct appearance here on November 22 and 29. Soon after sunset on November 22 (at 4.30 p.m.), a crimson glow was seen in the direction of south-west, and while everybody was supposing that some large printworks lying in that direction were on fire, the glow was getting more intense, and at 5 p.m. the whole of the western sky assumed a bluish purple hue which rose up to the zenith while the sun was sinking lower, so that the glow could be attributed only to an atmospheric phenomenon. About an hour after sunset the colour of the sky was almost violet, with which the phenomenon disappeared.

According to German papers, a phenomenon of this kind and intensity was never before observed in Central Europe. Dr. Assmann, director of the Meteorological Observatory, Madgeburg, attempts to explain these phenomena by the reflection of sunlight from the upper strata of our atmosphere, highly saturated with aqueous vapour, owing to its comparatively high temperature. The phenomenon could not be attributed to electrical causes, as at that time not the slightest magnetic disturbance could be observed at the Prague Observatory. In the spectrum of this light uncommonly strong "rain bands" were seen. As the sun was about $18 \frac{3}{4}^{\circ}$ below the horizon when the phenomena began (before sunrise) or ceased (after sunset), the reflection was calculated to 
have taken place at a height of about fifty English miles.

Does it not strike you that the glow was observed at earlier periods the more we advance towards the eastthe source of the late Java eruptions? B. BRAUNER

Bohemian University, Prague, December 18, 1883

THE late splendid sunsets which have so vividly attracted the attention of men of science and of the general public were so remarkable and of so long a duration in the clear atmosphere of the Castilian tableland, where sunsets are usually dull, that they have not failed to impress observers with the notion that they were due to other causes than those of common atmospheric refraction and reflection.

When the phenomena had already lasted four or five days, I read Mr. Symons' letter, published in the Times of the Ist inst., and I thought that possibly evidence might be obtained towards the confirmation of this theory if the sediment of fresh-fallen snow was thoroughly investigated ; for if the dust of Krakatoa was really reflecting in the higher regions of the atmosphere the sun's rays, some of it must necessarily be descending towards the earth.

Luckily on the 7 th of this month, and when the phenomenon was at its height, and had already lasted for about eight days, there vas a fall of snow at Madrid, of which I naturally profited, submitting it to a thorough investigation, the results of which, I think, will throw some light on so remarkable a phenomenon.

The snow analysed was obtained from what had fallen on some zinc plates before the exposed windows to the north of my house, which is situated at the extreme north end of the town, where there are no buildings facing it, and also from what my friend Dr. Francisco Quisoga gathered from the windows of his house, situated about a mile to the south-east of mine; and in both the same substances were found.

The snow yielded about a litre of water, which, when the sediment had collected, was decanted, and the solid part dried at a temperature below that of boiling water. The dry powder was then tested for magnetism and it was found to be extremely magnetic. It was then incinerated on platinum foil to a bright red heat so as to destroy organic substances, and the remaining dust was then submitted to microscopical investigation. The greater part of it is made up of what probably is the natural dust of the atmosphere of Madrid ; of particles of mica, generally brown, and similar to that of the Guadarrama range, and in various states of decomposition, splinters of quartz and felspar, the greater part of it orthoclase, some small fragments of tourmaline, magnetic iron, and fragments of diatoms. Besides these mineral substances, which may probably be traced to the rocks forming the vicinity of the capital, some others were found for the presence of which it is difficult to account. The most remarkable are small particles of a foliated mineral of a yellowish colour, perceptibly dichroic, and which between crossed Nichols is extinguished when the cleavage traces are parallel to the principal section of the polarising Nichol; the interference colours being of bright blue, and red, and yellow colours. Treated by boiling hydrochloric acid for twenty minutes, not a trace of action was perceived. These characters are all referable to a rhombic pyroxene, and judging from its dichroism this substance may be taken for a hypersthene, which has besides a most striking resemblance to volcanic bypersthene. In addition to this mineral, small particles are found which appear to be referable to common pyroxene of a yellowish colour, of active action in polarised light, and the extinction not taking place parallel to what seem to be the edges of the prism. Besides these minerals some corpuscles are found of hardly any action on polarised light, and sometimes ful! of globular concretions and other kinds of microliths, which, if seen in products of a volcanic region, I would not hesitate in considering of volcanic origin.

These are the principal substances which an investigation of the sediment of the snow which fell in Madrid on the 7 th inst. have revealed, and though I am far from asserting that what appears to be foreign to the atmosphere of this part of the world is referable to the dust of Krakatoa, if further analyses in other parts of the world should show these same substances floating in the atmosphere, there would be powerful reasons for inferring that the gorgeous sunsets of the past months have been brought about in consequence of that stupendous display of the volcanic forces of our globe.

It is already a remarkable coincidence that hypersthene should have been found both by MM. Daubrée and Renard in their respective analyses of the ashes collected in the vicinity of Krakatoa.

Madrid, December 22, 1883

COMPLYING with the request contained in your "Notes" of December I3 (p. 157), I would say that the appearances, already fully described by so many of your correspondents, commenced here on December I. On that day I made an entry in my note-book as follows :- "Perfectly calm at sunset, with a light haze of a rose tint rolling away from overhead towards the west-south-west horizon. The colours of the sky were a very pale green, red, gold, and pink; and, as the light faded away, the southwest was one mass of deep rich red. The crescent moon (a little over eighteen days old) in the refractor was of a pale green colour, and the bright limb seemed to extend to an extraordinary distance round the dark body. Barometer falling."

Again: "December 2.-Sky clouded over by I p.m. Sunset, as seen between breaks in the clouds, was again of a deep rich red. Barometer steady."

"December 3.--Rainy and very dull. Barometer steady."

"December 4.-Sunset, as seen through the clouds along the horizon, was again of a deep red colour, gradually shading off into a pale rose tint towards the zenith. The moon, Fomalhaut, and Vega seemed to float in a pale rose sea; whilst thin fleecy clouds as they drifted across the moon's face were of a beautiful pale green. This appearance - as did that on the 1 st-lasted for about an hour and a quarter after sunset; the rest of the sky being covered with clouds, some faintly reflecting the various tints. Barometer falling."

I should not omit to mention that the sunrises were also, more or less, of similar character. Since the 4 th we have had very bad weather; gales from both north and south, heavy rains, and snow. Yet the sky, when occasionally glimpsed at sunset, seems to bear traces of the same appearances.

Constantinople, December 21, I883

IN addition to the remarkable sunsets which have led to such a large amount of correspondence in NATURE and elsewhere, there is another and possibly a related phenomenon to which my attention has been directed during the last few weeks. From country friends I learn that the nights, in the absence of the moon, and even when cloudy, have been remarkably light for the time of year. I cannot profess to have witnessed this phenomenon myself, living as I do in the midst of London, where the perpetual glare of gas renders any satisfactory estimate of the atmospheric luminosity quite hopeless. It would be interesting, however, to learn whether other observers more favourably located have noticed this effect. It occurred to me that the phenomenon might perhaps be connected with the volcanic dust theory of the sunsets, being, in fact, a result of the slight phosphorescence of this dust. Whether the latter exhibits any degree of phosphorescence could be readily deter- 
mined by those who are fortunate enough to possess a specimen, by means of Becquerel's phosphoroscope. R. MELDOLA 2 I, John Street, Bedford Row, W.C., Dec. 31, 1883

IN corroboration of what Messrs. Beyerinck and Van Dum noticed at Wageningen in connection with the late storm, I write to tell you that on the morning of December 12, after the heavy rain which accompanied the gale had cessed, the windows of my house, which is isolated and exposed, were covered with a grayish sediment, just as your correspondents describe it. It will be interesting, now that attention has been drawn to the fact, to know if the phenomenon, the result no doubt of dust brought down by the rain, has been observed elsewhere.

Highfield, Gainsborough, December 24,1883

I SUBMIT to you two slides of dust from windows, deposited during the storm of December 12. When the cuntained salt crystals are dissolved by adding distilled water, the appearance much resembles that recorded in NATURE of December 20 . The material, scraped from windows cleaned just before the storm, where the original drop-marks are still unaltered, was put on the cleaned slides, and a drop of distilled water added. Should my surmise be confirmed, and any of your reuders desire to have specimen slides, I would forward a limited number on receipt of sixpence each to cover postage and trouble. Descriptions I have received from America, either in letters or newspaper cuttings, show an identical sequence of appearances. At Poughkeepsie, on the Hudson, the fire engines were called out on the morning of November 27 , and "this spectacle has been witnessed every clear evening for several days past, generally between a quarter past five and six o'clock." A letter from Dorset, Vermont, November 29, describes "a very unusual exhibition in the skies for the past three or four evenings. It has been clear, and the colouring intense, from flame to a delicate pink, and the clouds off at a distance would look light green. ... It gave an impression of an intense fire the other side of the West Mountains, and colouring the entire sky."

York, December 22, I883

J. EDMUND CLARK

THE accompanying extract may be of service to you. Sapporo is in the northernmost island of Japan (Yeso), in lat. $43^{\circ} \mathrm{N}$, an 1 long. (circa) $141^{\circ} \mathrm{E}$. As the telegraph ramifies through all parts of Japan, it is improbable that any considerab:e local eruption would have taken place to account for the phenomenon without news of it having also reached the Official Gazette. ROBERT BEADON

I I, Lee Park, Lee, Kent, December 14, 1883

Extract from Japan Weekly Mail (published in Yokohama) of October 20, 1883. (The Official Gazette is the Government gazette published in Japanese.) - "The Official Gazette states that, since the I3th inst., a constant haze has pervaded the atmosphere of Sapporo, and that the sun and moon are of a blood-red colour. Clouds of ashes fall continuously. The phenomenon is ascribed to some volcanic eruption."

\section{NOTES}

PRUF. OWEN has received the honour of K.C.B. as an acknnw ledgment of his exinent services for sixty years to science and the public interests.

Prof. W. H. Mackintosh has teen elected to the Professorship of Comparative Anatomy in Trinity College, Dublin, vice Prof. Macalister, F.R.S., who resigned on his appointment to the Anatomy Chair at Cambridge.

By the death of the well-known mathematician, the Rev. W. Roterts, M.A., the Rev. Richard Townsend, M.A., F.R.S., becomes a Senior Fellow of Trinity College, Dublin, thereby vacating the Professorship of Natural Philosophy held by him since 1870 .

THe vacancy in the Professorship of Geology and Mineralogy in the University of Dublin has teen filled by the election of Prof. Sollas, of University Colle ge, Bristol. 'This appointment will give great sati-faction, and will afford Mr. Sollas large opportunities for palæontological research ; the large collections of fossil plants and vertebrates in the museum in Dublin remaining to this day almost unknown.

ThE Swedish Government intend to establish a botanicophysiological station in the north of Sweden for the study of the flora and the diseases of the crops in that part of the country.

The Finnish Government have ordered a steamer to be specially built in Sweden for the scientific researches about to be prosecuted in the Baltic.

M. Hovzeau, who was only recently appointed director of the Brussels Observatory, has resigned his post, and it is reported that M. de Konkjly of Gzalla Observatory, Hungary, will succeed him.

Prof. MAURICE Levy has been numinated member of the Paris Academy of Sciences in the Section of Mechanics.

THE Prince of Wales, as President of the Society of Arts, has transmitted to Lady Siemens the resolution pa:sed after the death of Sir William Siemens, by the Council of that Suciety, and in doing so has expressed his own appreciation of Sir Willia:n Siemens's labours.

Science had quite a field.day in Perth on December 20, when the Natural History Society of the Fair City formally opened its museum. Prof. J. Geikie of Edinburgh, who was for some time president of the Society, opened the proceeding with an address in which he pointed out what such a local museum should be. Other speakers followed, and from the 2oth to the 23rd was an almost continuous conversazione, in which exhibitions, demonstrations, and lectures were given. 't he electric light played a prominent part, and the objects brough. together for the ins'ruction and enjoyment of the many vi itor; represented all departments of science. The enterprise of the Perthshire Scciety is exceptional, and they have reason to be proud of their museum, reading, lecture, and other rooms, all of which, we have no doubt, will be put to excellent practical uses.

THE meteorological observations taken during October, $188_{3}$, at St. Ignatius' College, Malta, by the Rev. James Scoles, S.J., have been received. For the month the means were-pressure, 30.283 inches; temperature, $67^{\circ} .98$; daily range, $10^{\circ} \cdot 2$; elastic force of vapour, 0.498 inch, and humidity, 76 ; rainfall, 2.67 inches, and days of rain, 12 ; velocity of wind per hour, $8 \frac{1}{2}$ miles; sky, a third covered with cloud; temperature of sea, $72^{\circ} \circ$, with a monthly range of $4^{\circ} \circ$; and thunderstorms and other electrical phenomena on the 4 th, Ioth, IIth, I 2 th, $13^{\text {th }}, 15^{\text {th }}, 26$ th, and $30 \mathrm{~h}$. Atmospheric pressure was thus fully a fourth of an inch below the mean, temperature $3^{\circ}$. lower than usual, and rainfall about half an inch less. This Society has peculiar facilities for prusecuting meterrol gical and other researches through its widely scattered seminaries and colleges, and we have the greatest pleasure in noting the increasing readiness with which its services are given to science.

Mr. H. H. JOHNSTON will give a discourse on "Kilimanjaro, the snow-clad Mou itain of Equatorial Africa," at the Royal Institution, on Friday evening, January 25. Prof. Bonney's di:course on "The Building of the Alps," announced fur that evening will be given on April 4. 